\title{
Antimicrobial Effect of Aqueous and Ethanolic Extracts of Satureja Bachtiarica on Some Pathogenic Bacteria in Vitro
}

\author{
Maryam Heidari-Sureshjani ${ }^{1,}$; Faride Tabatabaei-Yazdi ${ }^{1}$; Behrooz Alizadeh-Behbahani ${ }^{1}$; Ali \\ Mortazavi $^{1}$ \\ ${ }^{1}$ Department of Food Sciences and Technology, Faculty of Agriculture, Ferdowsi University of Mashhad, Mashhad, IR Iran \\ *Corresponding author: Maryam Heidari-Sureshjani, Department of Food Sciences and Technology, Faculty of Agriculture, Ferdowsi University of Mashhad, Mashhad, IR Iran. \\ E-mail: maryam.heidari67@yahoo.com
}

Received: January 11, 2014; Accepted: June 17, 2014

\begin{abstract}
Background: Essences and extracts of herbs, possess a variety level of biological activities, in addition the antimicrobial activities of a large number of these have been proved. With regard to the biologically active compounds and traditional use of the Satureja bachtiarica, it seems that this plant has significant antimicrobial effects.

Objectives: The aim of this study is to evaluate the antimicrobial effect of aqueous and ethanolic extracts of S. bachtiarica against Enterobacter aerogenes, Bacillus subtilis and Listeria innocua of the important food pathogen.

Materials and Methods: In this experimental study, antimicrobial effect of extracts was evaluated by two methods, Collins method and disk agar diffusion method on Enterobacter aerogenes ATTC 13048, Listeria innocua ATTC 33090 and Bacillus subtilis PTCC 1720. The minimum inhibitory concentration (MIC) and minimum bactericidal concentration (MBC) determined using a dilution method. Statistical analysis was carried out by analysis of variance (ANOVA) technique.

Results: All ethanolic extract concentrations had an inhibitory effect on the disk agar diffusion method. In Collins method ethanolic extract, prevented the growth of both strains on medium. The MBC of ethanolic extract of S. bachtiarica for B. subtilis and L.innocua was 16 and $32 \mathrm{mg} / \mathrm{mL}$ respectively, and for E. aerogenes was $64 \mathrm{mg} / \mathrm{mL}$. But the $\mathrm{MBC}$ of aqueous extract of S. bachtiarica for B. subtilis and L. innocua was 32 and $64 \mathrm{mg} / \mathrm{mL}$, respectively and for E. aerogenes was $128 \mathrm{mg} / \mathrm{mL}$.

Conclusions: The S. bachtiarica extract showed the more effective impact on the growth of B. subtilis PTCC 1720 and L. innocua ATTC 33090 than E. aerogenes ATTC 13048 ( $\mathrm{P}<0.05)$. The results indicated that ethanolic extract of $S$. bachtiarica had maximum effect on Gram positive bacteria B. subtilis PTCC 1720 and L. innocua ATTC 33090.
\end{abstract}

Keywords: Satureja bachtiarica; Aqueous extract; Ethanolic extract; Antimicrobial effects; Pathogenic bacteria, Collins method

\section{Background}

During the last several decades, natural products with antimicrobial effect have been investigated in order to eliminate the use of synthetic antibiotics which cause the resistance of microorganisms and have adverse effects on the human health. Aromatic plants have been known for a very long time and they are used in phototherapy and food preservation [1]. In many cases, the components contained in plants' extract play a role as defensive mechanisms of the plant against predation by microorganisms, insects and herbivores. Some of the components, such as terpenoids, will cause an aromatic plant; plant pigment is related to the existence of other components such as quinones and tannins. Many components are responsible for plant flavor (e.g. the terpenoid capsaicin from chili peppers). Aromatic plants have been known about for a very long time. Owning to their aromatic and antiseptic properties, they are used as spices, natural food preservatives, as well as for aromatherapy and for different medical purposes in the perfume industry. Savory species produce antimicrobial secondary metabolites, essential oils, either as a part of their normal program of growth and development or in response to pathogens' attack or stress [2].

Satureja bachtiarica has a relatively wide distribution in Iran and has been collected from West, Central, and Southwest provinces of Iran. There are about 30 species of Satureja in the world that S. bachtiarica is an endemic species of this genus in Iran. It can be used for removal of state weakness and gastric torsion. It can also be used to exploit digestive and intestinal fermentation and flatulence [3]. Due to the presence of secondary metabolites such as flavonoids, steroids, terpenoids and tannins they have been known for their healing properties for a long time and have been used as traditional folk remedies to treat various ailments such as cramps, muscle pains, nausea indigestion, diarrhea and infectious diseases [4].

Nowadays, in the medicinal plants, it provides the bountiful resource of active compounds for the pharma-

Copyright (c) 2015, Zahedan University of Medical Sciences. This is an open-access article distributed under the terms of the Creative Commons Attribution-NonCommercial 4.0 International License (http://creativecommons.org/licenses/by-nc/4.0/) which permits copy and redistribute the material just in noncommercial usages, provided the original work is properly cited. 
ceutical, cosmetics, food industries and more recently in agriculture for pest control [5]. Herbal products from medicinal plants are preferred because of less testing time, higher safety, efficiency, cultural acceptability and lesser side effects. The chemical compounds contained in herbal products are a part of the physiological functions of living organisms, and hence they are believed to have better compatibility with the human body [6, 7].

\section{Objectives}

The aim of this study is to evaluate the antimicrobial effect of aqueous and ethanolic extracts of S. bachtiarica against Enterobacter aerogenes, Bacillus subtilis and Listeria innocua of the important food pathogen.

\section{Materials and Methods}

Preparation plant: In this experimental study, $S$. bachtiarica was collected from the central Zagros region of western Iran (Chaharmahal and Bakhtiari province) in March 2013 and taxonomic identification was performed by the faculty of science herbarium, Ferdowsi University of Mashhad, Iran.

Extract preparation: Maceration method was used to prepare extracts. The amount $50 \mathrm{~g}$ of S. bachtiarica powder was added to $250 \mathrm{~mL}$ ethanol $96 \%$ or water. The mixture of ethanolic and aqueous extracts was preserved at laboratory temperature for 24 hours. Then the extract was filtered using paper filters and centrifuged in 9000 $\mathrm{g}$ for 15 minutes [8].

Determination dry weight of alcoholic and aqueous Satureja bachtiarica extracts: At first, the weight of a tube was measured, and then $1 \mathrm{~mL}$ of alcoholic and aqueous extracts were poured in it. The contents of the tube were dried at room temperature. Having dried the extract, the researchers weighed the tubes again. Weight differences are equivalent with weight of $1 \mathrm{~mL}$ alcohol extract. Average of three replicates, was considered as the dry weight of the extract [9].

Source of microorganisms: The applied bacterial strains were E. aerogenes ATTC 13048, B. subtilis PTCC 1720 and L. innocua ATTC 33090 for each test.

Preparation of microbial suspension: To prepare the microbial suspensions, cultivation for 24 hours from each microorganism is needed. So, 24 hours before experiments, microorganisms were inoculated from storage medium on nutrient agar medium slope. After 24 hours, the cultures were washed by Ringer solution and microbial suspensions were prepared. Then some of the bacterial suspension was poured in sterile tubes containing Ringer solution and its turbidity was measured by spectrophotometer at $530 \mathrm{~nm}$ wavelength. It was diluted by Ringer solution until the solution turbidity equalizes with 0.5 McFarland standard solution [10].

Evaluation of antimicrobial activity: The antimicrobial effects of S. bachtiarica were assayed according to Collins method and disk agar diffusion methods. Then $0.2 \mathrm{~g}$ of ethanol extract, were added to $5 \mathrm{~mL}$ of sterile distilled water. After that, it was stirred with vortex system to assist being steady, subsequently $1 \mathrm{~mL}$ of this solution was added to sterile plates. The final concentration of the extract was $2000 \mathrm{mg} / \mathrm{mL}$. At the next step, the sterilized Mueller Hinton Agar (Merck-Germany) medium were added to the plates and placed at room temperature. One loop of each standard strain culture media was cultured inoculums on these medium. The plates were incubated for 24 hours at $37^{\circ} \mathrm{C}$. The culture with extract and without bacteria was used as control [11]. In the disk agar diffusion method $1.5 \times 10^{8} \mathrm{CFU} / \mathrm{mL}$ (equivalent to 0.5 McFarland standards) of standard culture of each strain was cultured on agar surface at the first step, then it was spread on the surface of agar by sterile glass spreader. After the inoculated plates had dried sufficiently the discs were kept over the agar plates using sterile forceps at various concentrations $(20,40,60$ and $80 \mathrm{mg} / \mathrm{mL})$. Antibacterial activity was observed as inhibition zone on Petri plates. Size of the inhibition zone was measured in millimeters using a metric ruler [12].

Minimum inhibitory concentration (MIC): MIC was determined according to agar dilution method [13]. Various concentrations $(20,40,80,160,320,640,1280,2560$ $\mathrm{mg} / \mathrm{mL}$ ) of extracts was prepared in $10 \mathrm{~cm}$ experimental tubes. Each tube contained $9 \mathrm{~mL}$ of Muller Hilton was sterilize by autoclaving. After cooled, $1 \mathrm{~mL}$ of different concentrations $(2,4,8,16,32,64,128,256 \mathrm{mg} / \mathrm{mL})$ of each extract was added to each tube. The tubes were incubated for 24 hours at $37^{\circ} \mathrm{C}$ [14]. The lowest concentration that did not permit any visible growth when compared with the control was considered as the MIC.

Minimum bactericidal concentration (MBC): MBC was determined according to agar dilution method [15] with slight modifications. The MBC were determined by incorporating various concentrations of extracts (2 - 256 $\mathrm{mg} / \mathrm{mL}$ ) in Muller Hilton Broth for bacteria. All the tubes which showed no visible growth were cultured using pour plate method [14]. The MBC was regarded as the lowest concentration of the extract that prevented the growth of any bacteria colony on the solid medium.

Statistical analysis: The experimental results were expressed by Mean \pm SD. The data were analyzed using one way analysis of variance (ANOVA) using SPSS-18. In the one-way ANOVA, we have tested the values of a quantitative variable in the different groups. In the technique, only one variable factor (concentration) is involved and we evaluated its effects on the dependent variable (inhibition zone diameter). In this study, four different levels of concentration of aqueous and ethanolic extracts have been used. Therefore, it can be said that the four groups have been tested in terms of a quantitative variable.

\section{Results}

The results of the antimicrobial effects of ethanolic and aqueous extracts, by using the method of Collins method were show on in Table 1 . The results showed $2000 \mathrm{mg} / \mathrm{mL}$ 
concentration of ethanolic extract, were quite effective on reduce of growth E. aerogenes, B. subtilis and L. innocua and were had prevent growth over the medium.

The aqueous extract, only had antimicrobial effect in $2000 \mathrm{mg} / \mathrm{mL}$ concentration on growth of, B. subtilis. The results the antimicrobial effects of ethanolic and aqueous $S$. bachtiarica extracts, by the agar diffusion method were presented in Table 2. The results the MIC and MBC of ethanolic and aqueous S. bachtiarica extracts were presented in Tables 3 and 4.

Table 1. Antimicrobial Effects of $2000 \mathrm{mg} / \mathrm{mL}$ Ethanolic and Aqueous Satureja Bachtiarica Extracts Concentrations on Enterobacter aerogenes, Bacillus subtilis and Listeria innocua (Using the Method of Collins method) ${ }^{\mathrm{a}}$

\begin{tabular}{lcc}
\hline & Microorganism & Satureja bachtiarica extract \\
\hline Aqueous & Enterobacter aerogenes & - \\
Aqueous & Bacillus subtilis & + \\
Aqueous & Listeria innocua & + \\
Ethanolic & Enterobacter aerogenes & + \\
Ethanolic & Bacillus subtilis & + \\
Ethanolic & Listeria innocua & + \\
\hline a $(-)$ in table showed the growth of bacteria on culture and the lack of antibacterial activity of Satureja bachtiarica extracts, $(+)$ in table showed no \\
bacterial growth on culture and antibacterial activity of Satureja bachtiarica extracts.
\end{tabular}

Table 2. Average Diameter (mm) of Microbial Free Zone Area of Aqueous and Ethanolic Satureja bachtiarica Extract, on Enterobacter aerogenes, Bacillus subtilis and Listeria innocua (Disk Agar Diffusion Method) ${ }^{\mathrm{a}, \mathrm{b}}$

\begin{tabular}{|c|c|c|c|c|c|}
\hline \multirow[t]{2}{*}{ Type of Extract } & \multirow[t]{2}{*}{ Microorganism } & \multicolumn{4}{|c|}{ The Concentration of Satureja Bachtiarica Extracts, mg/mL } \\
\hline & & 20 & 40 & 60 & 80 \\
\hline Aqueous & Enterobacter aerogenes & - & - & $10.30 \pm 0.55$ & $11.40 \pm 0.57$ \\
\hline Aqueous & Bacillus subtilis & $8.60 \pm 0.58$ & $9.50 \pm 0.57$ & $11.10 \pm .55$ & $12.70 \pm 0.28$ \\
\hline Aqueous & Listeria innocua & - & $8.40 \pm 0.58$ & $10.20 \pm 0.28$ & $11.60 \pm 0.53$ \\
\hline Ethanolic & Enterobacter aerogenes & - & $9.80 \pm 0.50$ & $10.80 \pm 0.53$ & $11.50 \pm 0.28$ \\
\hline Ethanolic & Bacillus subtilis & $11.00 \pm 0.58$ & $12.60 \pm 0.28$ & $13.90 \pm 0.57$ & $14.30 \pm 0.50$ \\
\hline Ethanolic & Listeria innocua & $10.70 \pm 0.53$ & $11.80 \pm 0.55$ & $12.50 \pm 0.58$ & $13.00 \pm 0.52$ \\
\hline
\end{tabular}

a Data are presented as Mean \pm SD and $\mathrm{n}=3$.

b (-): No inhibitory effects was shown.

Table 3. Minimum inhibitory concentration (MIC) of aqueous and ethanolic extract of Satureja bachtiarica on Enterobacter aerogenes, Bacillus subtilis and Listeria innocua a,b

\begin{tabular}{|c|c|c|c|c|c|c|c|c|c|c|}
\hline \multirow[t]{2}{*}{ Type of Extract } & \multirow[t]{2}{*}{ Bacteria Species } & \multicolumn{9}{|c|}{ Concentration, $\mathrm{mg} / \mathrm{mL}$} \\
\hline & & 2 & 4 & 8 & 16 & 32 & 64 & 128 & 256 & Control \\
\hline Aqueous & Enterobacter aerogenes & - & - & - & - & - & + & + & + & - \\
\hline Aqueous & Bacillus subtilis & - & - & - & - & - & + & + & + & - \\
\hline Aqueous & Listeria innocua & - & - & - & + & + & + & + & + & - \\
\hline Ethanolic & Enterobacter aerogenes & - & - & - & - & + & + & + & + & - \\
\hline Ethanolic & Bacillus subtilis & - & - & + & + & + & + & + & + & - \\
\hline Ethanolic & Listeria innocua & - & - & - & + & + & + & + & + & - \\
\hline
\end{tabular}

$\mathrm{a} n=3$.

$\mathrm{b}_{+}$: Inhibition; -: No inhibition.

Table 4. Minimum Bactericidal Concentration (MBC) of Aqueous and Ethanolic Extract of Satureja Bachtiarica on Enterobacter aerogenes, Bacillus subtilis and Listeria innocua ${ }^{\mathrm{a}, \mathrm{b}}$

\begin{tabular}{|c|c|c|c|c|c|c|c|c|c|c|}
\hline \multirow[t]{2}{*}{ Type of Extract } & \multirow[t]{2}{*}{ Bacteria Species } & \multicolumn{9}{|c|}{ Concentration, $\mathrm{mg} / \mathrm{mL}$} \\
\hline & & 2 & 4 & 8 & 16 & 32 & 64 & 128 & 256 & Control \\
\hline Aqueous & Enterobacter aerogenes & - & - & - & - & - & - & + & + & - \\
\hline Aqueous & Bacillus subtilis & - & - & - & - & + & + & + & + & - \\
\hline Aqueous & Listeria innocua & - & - & - & - & - & + & + & + & - \\
\hline Ethanolic & Enterobacter aerogenes & - & - & - & - & - & + & + & + & - \\
\hline Ethanolic & Bacillus subtilis & - & - & - & + & + & + & + & + & - \\
\hline Ethanolic & Listeria innocua & - & - & - & - & + & + & + & + & - \\
\hline
\end{tabular}

${ }^{\mathrm{a}} \mathrm{n}=3$.

b +: Inhibition; -: No inhibition. 


\section{Discussion}

Based on the findings in this study, ethanolic extract of S. bachtiarica have antimicrobial activity on the studied microorganisms. The results show that ethanolic extract of $S$. bachtiarica in all concentrations $(20,40,60$ and $80 \mathrm{mg} / \mathrm{mL}$ ) had the inhibitory effect on B. subtilis and L. innocua. The results show that aqueous extract of S. bachtiarica at 60 and $80 \mathrm{mg} / \mathrm{mL}$ had the inhibitory effect on E. aerogenes, however, 20 and $40 \mathrm{mg} / \mathrm{mL}$ have no significant antimicrobial effect on E. aerogenes. In addition, the $20 \mathrm{mg} / \mathrm{mL}$ concentration is not able to prevent the growth of L.innocua on culture.

The MIC of ethanolic extract of S. bachtiarica for B. subtilis and L. innocua was 8 and $16 \mathrm{mg} / \mathrm{mL}$, respectively and for E. aerogenes was $32 \mathrm{mg} / \mathrm{mL}$. But MIC of the aqueous extract of S. bachtiarica for B. subtilis and L. innocua was 16 and $32 \mathrm{mg} / \mathrm{mL}$, respectively and for E. aerogenes was $64 \mathrm{mg} /$ $\mathrm{mL}$. Depending on the type of microorganisms, the antimicrobial effect of the extracts was different, therefore, the Gram positive bacteria B. subtilis and L. innocua, had a higher sensitivity compared to Gram negative bacteria E. aerogenes. The plants are sources of biologically active substances. Essential oils can be a significant source of a great diversity of chemical components equipped with antimicrobial capacity, the S. bachtiarica can be applied in therapy of the infectious diseases as antibiotic. Essential oils can also have application in food industries not only as aromatizing but also as preservative of foodstuffs.

In general, the previous studies have posited that the Gram positive bacteria are more sensitive to plant oil and extracts than the Gram negative ones, due to differences in cell structure of Gram negative and Gram positive bacteria. Gram positive bacteria have more mucopeptide in their cell wall composition while Gram negative bacteria have only a thin layer of mucopeptide and most of their cell structure is lipoprotein and lipopolysaccharides. Thus, Gram negative bacteria are more resistant $[16,17]$. Moreover, Tian et al. investigated the antibacterial effects of aqueous and ethanolic extract of Galla Chinesis (a medicinal plant native to China). They reported that Gram positive bacteria (B. cereus, S. aureus, B. subtlis) are more sensitive than Gram negative bacteria (Escherichia coli, Shigella dysentery) to plant extracts. This result is consistent with the findings of this study [18].

Also, ethanolic extract compared to the aqueous extract was more effective and has a greater inhibitory effect. Alizadeh-Behbahani et al. reported that ethanolic extract compared to the aqueous extract was more effective and have a greater inhibitory effect [19]. Attempting to study the antibacterial activity of aqueous and ethanolic extract of Kelussia odsoratissima against food borne and food spoilage bacteria, Heidari-Sureshjani et al. also reported that ethanolic extract of plant had exhibited broad spectrum activity against isolates as compared to aqueous extract [14].

Boroujeni et al. pointed that the extracts from S. bachtiarica and Thymus daenensis exhibited inhibitory effect on fungal growth, suggesting that the studied plant extracts are potentially a safe and natural source of antifungal agents. Some of these plants were more effective than traditional antimicrobial to combat the pathogenic microorganisms [20]. Sefidkon et al. showed the high antimicrobial effect of essential oils. It seemed that the presence of thymol, carvacrol, P-cymene and gamma-terpinene in the oils caused their strong antimicrobial effect. Several mechanisms are discussed to explain the antimicrobial effect. Several studies have been performed concerning the antimicrobial activity of essential oils or extracts of other Satureja species [3]. Many of the previous studies demonstrated that the members of the genus Satureja show a high antimicrobial activity due to the presence of thymol, carvacrol and their precursors [21-23]. In conclusion, it can be suggested that S. bachtiarica extract in "in vitro" have considerable antimicrobial ability against the studied strains. In addition, more studies should be done "in Situ," in order to identify the effective dose of the extract on the microorganisms, and finally to introduce the extract as a natural and novel antimicrobial compound.

\section{Acknowledgements}

The authors wish to express their profound gratitude and thank sincerely to Research's Deputy of Ferdowsi University of Mashhad for providing the cost of this project and help to implementation of this project with code 2/16135 which adopted at 257th meeting of the Research Council of Agricultural faculty. The authors wish to express their profound gratitude to Ms. Afsharian who helps about experiments and Ms. Adele Heidari helped us to prepare samples.

\section{Funding/Support}

This study was supported by Ferdowsi University of Mashhad.

\section{References}

1. Matan N, Rimkeeree H, Mawson AJ, Chompreeda P, Haruthaithanasan V, Parker M. Antimicrobial activity of cinnamon and clove oils under modified atmosphere conditions. Int J Food Microbiol. 2006;107(2):180-5.

2. Mihajilov-Krstev T, Radnovic D, Kitic D, Stojanovic-Radic Z, Zlatkovic B. Antimicrobial activity of Satureja hortensis L. essential oil against pathogenic microbial strains. Arch Biol Sci. 2010;62(1):159-66.

3. Sefidkon F, Askari F, Sadeghzadeh L, Oulia P. Antimicrobial effects of the essential oils of Satureja mutica, S. edmondi and S. bachtiarica against Salmonella paratifi A and B. Iran J Biol.2009; 22(2): 249-258.

4. Bezic N, Samanic I, Dunkic V, Besendorfer V, Puizina J. Essential oil composition and internal transcribed spacer (ITS) sequence variability of four South-Croatian Satureja species (Lamiaceae). Molecules. 2009;14(3):925-38.

5. Nee M, Rice EL. Biological control of weeds and plant diseases: advances in applied allelopathy. Brittonia.1997;49(1):70.

6. Khanna S, Gupta SR, Grover JK. Effect of long term feeding of tulsi(Ocimum sanctum Linn) on reproductive performance of adult albino rats. Indian J Exp Biol. 1986;24(5):302-4.

7. World Health Organization. WHO traditional medicine strategy 
2002-2005.Geneva:WHO; 2005.

8. Ahmad I, Beg AZ. Antimicrobial and phytochemical studies on 45 Indian medicinal plants against multi-drug resistant human pathogens. J Ethnopharmacol. 2001;74(2):113-23.

9. Sattari M, Shahbazi N, Najjar S. [The antibacterial activity of methanolic extract of Eucalyptus against Pseudomonas aeroginosa]. Persian J Tarbiat Modarres. 2005;8(1):19-23.

10. Valero M, Salmeron MC. Antibacterial activity of 11 essential oils against Bacillus cereus in tyndallized carrot broth. Int J Food Microbiol. 2003;85(1-2):73-81.

11. Babayi H, Kolo I, Okogun J, Ijah U. The antimicrobial activities of methanolic extracts of Eucalyptus camaldulensis and Terminaliacatappa against some pathogenic microorganisms. Biokemistri. 2004;16(2):106-11.

12. Bauer AW, Kirby WM, Sherris JC, Turck M. Antibiotic susceptibility testing by a standardized single disk method. Am JClin Pathol. 1966;45(4):493-6.

13. Benger S, Townsend P, Ashford RL, Lambert P. An in vitro study to determine the minimum inhibitory concentration of Melaleuca alternifolia against the dermatophyte Trichophyton rubrum. Foot. 2004;14(2):86-91.

14. Heidari-Sureshjani M, Tabtabaei Yazdi F, Mortazavi SA. Antimicrobial effects of Kelussia odoratissima extracts against food spoilage bacteria. J Paramed Sci. 2014;5(2):116-20.

15. Espinel-Ingroff A, Fothergill A, Peter J, Rinaldi MG, Walsh TJ Testing conditions for determination of minimum fungicidal concentrations of new and established antifungal agents for Aspergillus spp.: NCCLS collaborative study. J Clin Microbiol. 2002;40(9):3204-8.

16. Tassou CC, Nychas GJE. Antimicrobial activity of the essential oil of mastic gum (Pistacia lentiscus var. chia) on Gram positive and Gram negative bacteria in broth and in Model Food System. Int Bioremediat Biodegrad.1995;36(3-4):411-20.

17. Ghalem BR, Mohamed B. Antibacterial activity of leaf essential oils of Eucalyptus globulus and Eucalyptus camaldulensis. Afr J Pharm Pharmacol . 2008;2(10):211-5.

18. Tian F, Li B, Ji B, Yang J, Zhang G, Chen Y, et al. Antioxidant and antimicrobial activities of consecutive extracts from Galla chinensis: The polarity affects the bioactivities. Food Chem. 2009;113(1):173-9.

19. Alizadeh Behbahani B, Tabatabaei Yazdi F, Shahidi F, Mohebbi M. Antimicrobial activity of Avicennia marina extracts ethanol, methanol \& glycerin against Penicillium digitatum (citrus green mold). Sci J Microbiol. 2012;1(7):147-51.

20. Boroujeni HA, Ghasemi Pirbalouti A, Hamedi B, Abdizadeh R, Malekpoor F. Anti-Candida activity of ethanolic extracts of Iranian endemic medicinal herbs against Candida albicans. J Med Plants Res. 2012;6(12):2448-52.

21. Adiguzel A, Ozer H, KiliC H, CetiN B. Screening of antimicrobial activity of essential oil and methanol extract of Satureja hortensis on foodborne bacteria and fungi. Czech J Food Sci. 2007;25(2):81.

22. Gulluce M, Sokmen M, Daferera D, Agar G, Ozkan H, Kartal N, et al. In vitro antibacterial, antifungal, and antioxidant activities of the essential oil and methanol extracts of herbal parts and callus cultures of Satureja hortensis L. J Agric Food Chem. 2003;51(14):3958-65.

23. Sahin F, Karaman I, Gulluce M, Ogutcu H, Sengul M, Adiguzel A, et al. Evaluation of antimicrobial activities of Satureja hortensis L.J Ethnopharmacol. 2003;87(1):61-5. 